\title{
INSIGHTS GAINED FROM CONFORMATIONAL ANALYSIS IN HETEROCYCLIC SYSTEMS
}

\author{
ERNEST L. ELIEL \\ Department of Chemistry, University of Notre Dame, \\ Notre Dame, Indiana 46556, U.S.A.
}

\begin{abstract}
A review of recent work in the conformational analysis of 1,3-dioxanes carried out at the University of Notre Dame is given. Work on 2-alkyl- and 2-alkoxysubstituted 1,3-dioxanes, 5-hetero-substituted 1,3-dioxanes and 5,5-geminally disubstituted 1,3-dioxanes is summarized. A novel four-component equilibrium approach to the evaluation of conformational energies is presented.
\end{abstract}

THE conformational features of the 1,3-dioxane and, to a lesser extent, the 1,3-dithiane six-membered heterocyclic rings have been investigated quite intensively during the last three or four years. Since our earlier work in this area has been published in detail ${ }^{1,2}$ and since several reviews of conformational analysis in heterocyclic systems are now available ${ }^{3-6}$, this summary will be concerned largely with recent and as yet largely unpublished work from the Notre Dame laboratories.

The 1,3-dioxane and 1,3-dithiane systems are convenient objects of study because, as shown in Figure 1, they are easy to synthesize with a wide variety of substituents in the 2-, 4- and 5-positions. Moreover, they show relatively simple n.m.r. spectra, the protons at $\mathrm{C}-2\left(\mathrm{X}-\mathrm{CH}_{2}-\mathrm{X}\right)$ usually resonating at appreciably lower field than those at $\mathrm{C}-4$ and $\mathrm{C}-6\left(\mathrm{X}-\mathrm{CH}_{2}-\mathrm{C}\right)$ which in turn, are at lower field than those at $\mathrm{C}-5\left(\mathrm{C}-\mathrm{CH}_{2}-\mathrm{C}\right)$. Equilibration by means of Lewis acid is also facile (Figure 2) and nearly independent of the type and degree of substitution. In our earlier work we had usually effected equilibration by means of boron trifluoride ( $\frac{1}{10}$ mole equivalent) in ether for the dioxanes ${ }^{1}$; in the case of dithianes, which are less basic, ether competed too effectively for the Lewis acid catalyst and it was necessary to employ chloroform as the solvent and to raise the temperature to effect equilibration in reasonable periods. We have since found that Amberlyst-15 (Rohm and Haas; a beaded polystyrenesulphonic acid resin) is a more convenient catalyst for dioxane equilibration (besides being insoluble and easily removed after reaction, it appears to be less destructive, in some cases, than boron trifluoride) and that the soft $\mathrm{acid}^{7}$, antimony trifluoride, is more effective in the equilibration of 1,3-dithianes (soft base ${ }^{7}$ !) than is the hard acid boron trifluoride 8 .

The insights gained from the conformational study of 1,3-dioxanes and 1,3-dithianes are concerned mainly with detailed experimental information regarding non-bonded interactions, including interactions of atoms containing unshared $p$-electrons (the ring oxygen or sulphur atoms) with 'fully 
saturated' atoms, such as carbon and hydrogen, with other atoms containing unshared $p$-electrons and with groups containing pi-electrons such as $\mathrm{C} \equiv \mathrm{N}$.

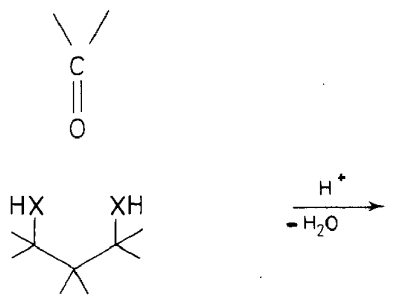

Figure 1

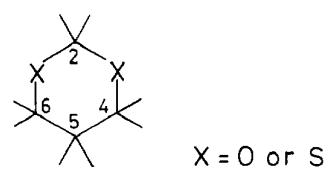

Also obtained is information on dipolar interactions in solvents of varying dielectric constant. Pertinent data will be presented; a complete understanding of the source of all the interactions will probably have to await comparison of experimentally observed with theoretically calculated values,

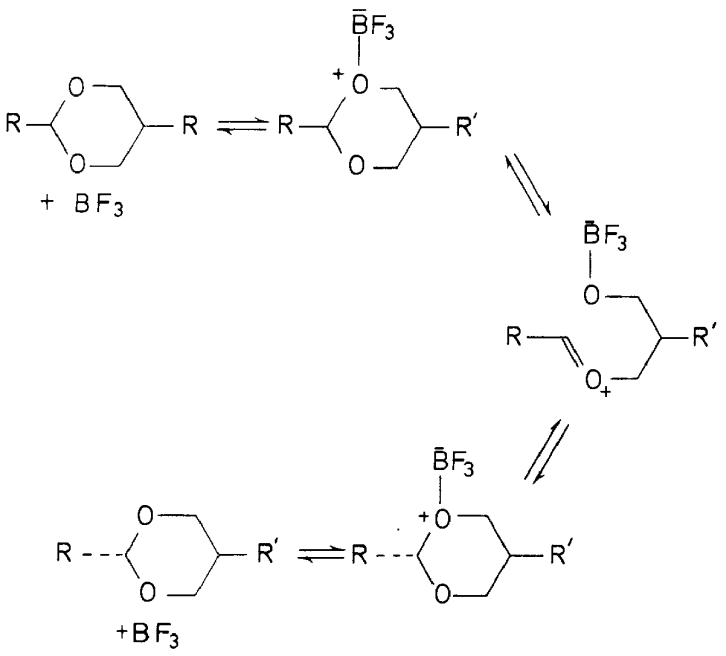

Figure 2

where the calculated values will probably be initially obtained by semiempirical procedures ${ }^{9 a}$, but eventually, hopefully by a more fundamental quantum-mechanical treatment ${ }^{9 b}$.

\section{2-SUBSTITUTED 1,3-DIOXANES}

The positions of equilibrium in a series of 2-substituted dioxanes (cis and trans isomers) are summarized in Table $1^{10}$. Within $\mathrm{C} 1$ to $02 \mathrm{kcal} / \mathrm{mol}$ (see below), the values given in Table 1 probably correspond to the true conformational equilibria of alkyl groups in 2-alkyl-1,3-dioxanes. It is noteworthy that the $-\Delta G^{0}$-values for 2-substituted 1,3-dioxanes are invariably higher than $-\Delta G^{0}$ values in cyclohexane (shown in Table 1 for 


\section{CONFORMATIONAL ANALYSIS IN HETEROCYCLES}

comparison); the reason lies in the shorter distance between the axial 2substituent and the syn-axial hydrogens at C-4 and C- 6 caused both by the shortness of the $\mathrm{C}-\mathrm{O}$ bond $(1.43 \AA)$ compared to $\mathrm{C}-\mathrm{C}(1.53 \AA)$ and by the puckering of the 1,3-dioxane ring in the $\mathrm{O}-\mathrm{C}-\mathrm{-O}$ region which was originally predicted $^{1}$ on the basis of model considerations and has now been confirmed ${ }^{11}$ by $x$-ray measurements which show a torsional $\mathrm{CO}-\mathrm{CO}$ angle of $63^{\circ}$ in 2-p-chlorophenyl-1,3-dioxane.

Table 1. 2-Substituted dioxanes ${ }^{10}$.

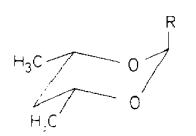

$$
\begin{gathered}
\mathrm{CH}_{3} \\
\mathrm{C}_{2} \mathrm{H}_{5} \\
i-\mathrm{C}_{3} \mathrm{H}_{7} \\
\mathrm{C}_{6} \mathrm{H}_{5} \\
\mathrm{X}-\mathrm{C}_{6} \mathrm{H}_{4} \\
\mathrm{X}=p-\mathrm{F}, p-\mathrm{Br}, p-\mathrm{CF}_{3}
\end{gathered}
$$

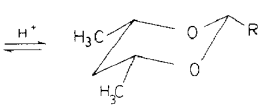

$\Delta G_{25}^{0}$

$-3.97^{a}$

$-4 \cdot 0$

$\Delta G_{\mathrm{cyc}}^{0}$

$-1 \cdot 70$

$-175$

$-2 \cdot 15$

$-3 \cdot 0$

a The value for methyl represents a refinement over the one earlier reported ${ }^{1}(-3.55 \mathrm{kcal} / \mathrm{mol})$ and is now in better agreement with that determined calorimetrically $(-407 \mathrm{kcal} /$ mole: ref 36$)$.

The value for phenyl in Table 1 is surprising, being considerably smaller than that for methyl, contrary to what is observed in the cyclohexane system.

\begin{tabular}{|c|c|c|c|}
\hline Conf. & $\mathrm{R}$ & $J_{a a}$ & $J_{e a}$ \\
\hline trans. & $\mathrm{Me}$ & $10 \cdot 6$ & 3.8 \\
\hline trans & $\mathrm{Et}$ & $10 \cdot 2$ & $4 \cdot 2$ \\
\hline trains & $i-\operatorname{Pr}$ & 10.4 & 42 \\
\hline cis & Et & $10 \cdot 0$ & 3.8 \\
\hline cis & $i-\operatorname{Pr}$ & 108 & 28 \\
\hline cis & $\mathrm{Ar}$ & $\begin{array}{r}96 \\
0102\end{array}$ & $\begin{array}{r}37 \\
\text { to } 42\end{array}$ \\
\hline trans & $\mathrm{Ar}$ & $\begin{array}{l}7.6 \\
8.2\end{array}$ & $\begin{array}{r}5.7 \\
\text { to } 65\end{array}$ \\
\hline cis & $\mathrm{Me}$, & 104 & 38 \\
\hline trans & $\mathrm{Ph}^{\mathrm{a}}$ & $9 \cdot 0$ & 42 \\
\hline
\end{tabular}
However, the fact is confirmed by the finding that in 2-phenyl-2,4,6-trimethyl1,3-dioxane (ketal from meso-2,4-pentanediol and acetophenone) the stereoisomer with axial phenyl and equatorial methyl is much more stable than that with axial methyl and equatorial phenyl ${ }^{12}$. A further surprise, shown in Table 2, lies in the fact that, whereas the coupling constants in the $\mathrm{C}-4$ /

Table 2. Coupling constants (in $\mathrm{Hz})^{10}$.

" Ketals derived from acetophenone. 


\section{ERNEST L. ELIEL}

C-5/C-6 region in the axially 2-substituted dioxanes with alkyl substituents are nearly the same as those of the isomers with equatorial alkyls, the same is not true for 2-phenyl-1,3-dioxane which shows a diminished $J_{a a}$ and an enhanced $J_{e a}$ when the 2-phenyl substituent is axial. It would appear that the more strained 2-axially substituted alkyldioxanes have the 'normal' 1,3:dioxane chair conformation whereas in the axial 2-aryl derivatives the chair is distorted by flattening. The phenomenon seems to be independent of the nature of the substituent on the phenyl ring (Tables 1,2 ) and is thus not sensitive to polar influences:

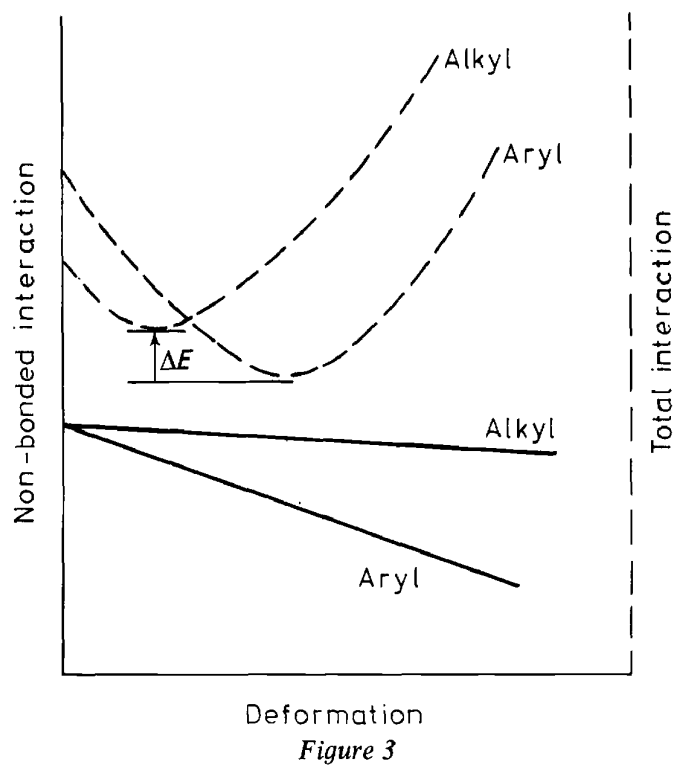

That the more distorted compound (axial 2-aryldioxane) is less strained that the less distorted one (axial 2-alkyldioxane) is quite unusual. It is possible that the van der Waals potential for an axially substituted 2-aryldioxane is unusually steep for relatively small deformations (Figure 3 ) and that this type of compound therefore improves its energy greatly by deformation, to the point that it becomes more stable than the corresponding 2-alkyl compound which has a normal potential and cannot gain as much by deforming itself. This explanation is not entirely unreasonable, in as much as the interaction of the phenyl group may be mainly an interaction of the pi-electrons which may be very sensitive to distance $\uparrow$. However, it must be admitted that the entire anomaly of the 2-aryl groups may be alternatively explained by some unusually strong steric strain in the equatorial phenyl isomer. This problem might perhaps best be resolved by heat-of-combustion measurements which should show whether the axial isomer is unusually

$\dagger$ This involves the assumption that the phenyl group confronts the syn-axial hydrogens 'broadside on'. The chemical shift of H-4 and H-6 (axial) in the axial 2-phenyl-4,6-dimethyl-1,3dioxane $(3.80$ p.p.m.) is nearly the same as the corresponding shift in the equatorial phenyl epimer ( 3.75 p.p.m.), presumably because the phenyl group is bent out sufficiently so that H-4 and $\mathrm{H}-6$ are no longer in the region of paramagnetic shielding. 
stable or the equatorial one unusually strained. Regardless of the source of the small strain difference, there is no question that the distortion of the axially 2-aryl-substituted dioxanes is real. In addition to coupling constants, comparison of experimental and calculated dipole moments in the case of the 2- $p$-trifluoromethylphenyl-4,6-dimethyl-1,3-dioxanes (Figure 4) confirms that the axially substituted isomer must have the phenyl group bent outward by a considerable angle.

\section{Dipole moments ${ }^{10}$}
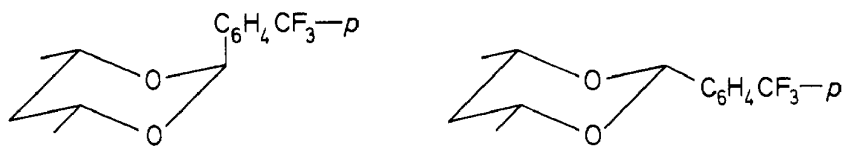

$$
\begin{array}{lll}
2.7 \mathrm{D} & \mu_{\text {exp }} & 4.5 \mathrm{D} \\
1.4 \mathrm{D} & \mu_{\text {salc }} & 4.4 \mathrm{D} \\
2.8 \mathrm{D} & \mu_{\text {calc }}, &
\end{array}
$$

bent out $20^{\circ}$

Figure 4

Equilibria in 2-alkoxy substituted 1,3-dioxanes ${ }^{10,13-15}$ are summarized in Table 3. In 4-methyl- and cis-4,6-dimethyl-2-methoxy-1,3-dioxanes, the axial methoxyl group is preferred over equatorial, despite the unquestionable steric repulsion which must exist in the axial isomer. Here. as in the glycosides ${ }^{16}$ and in the simpler 2-alkoxytetrahydropyran ${ }^{14}$, dipolar factors (less favourable interaction of the dipoles in the equatorial as compared to the axial alkoxy compound) more than overcome the steric factor. A detailed discussion of these dipolar factors in terms of the 'anomeric effect' ${ }^{16}$ or, in a more general sense, the 'rabbit ear' effect ${ }^{17}$ has been given elsewhere ${ }^{5}$. Here we shall discuss only two aspects of the data summarized in Table 3: the difference between the cis-4,6-dimethyl- and 4,4,6-trimethyl-2-methoxy1,3-dioxanes and the difference between the 4,6-dimethyl- and 5-t-butylsubstituted compounds.

That the axial isomer in 2-methoxy-4,4,6-trimethyl-1,3-dioxane is less stable than that in 2-methoxy-cis-4.6-dimethyl-1.3-dioxane is clearly due to the additional syn-axial methyl-methoxyl interaction in the former.

Table 3. Equilibria in 2-methoxy-1,3-dioxanes.

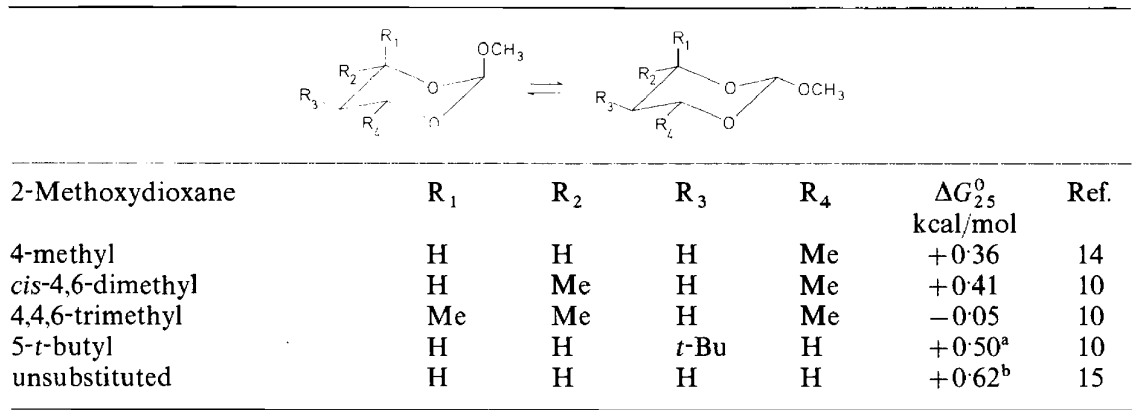

* Value corrected for conformational inhomogeneity: $0.60 \mathrm{kcal} / \mathrm{mol}$.

b From dipole moment. All other values are by direct equilibration. 
If we call this interaction $\mathrm{X}$, it is clear (see top of Table 3) that for the trimethyl compound: $\mathrm{X}+\mathrm{Me} / \mathrm{H}_{4}+\mathrm{MeO} / \mathrm{H}=\mathrm{Me} / \mathrm{H}_{4}+\mathrm{Me} / \mathrm{H}_{2}+\mathrm{A}+0.05$ where $\mathrm{A}$ is the anomeric effect and $\mathrm{Me} / \mathrm{H}_{2}=1 / 2 \times 4$ (see above) $=2$, whence

$$
\mathrm{X}+\mathrm{MeO} / \mathrm{H}=\mathrm{A}+2 \cdot 05
$$

For the dimethyl compound : $2 \mathrm{MeO} / \mathrm{H}+0.41=\mathrm{A}$

$$
\text { Subtracting (ii) from (i): } \quad \mathrm{X}-\mathrm{MeO} / \mathrm{H}=2 \cdot 46 \mathrm{kcal} / \mathrm{mol}
$$

i.e. the $\mathrm{MeO} / \mathrm{Me} s y n$-axial interaction exceeds $\mathrm{MeO} / \mathrm{H}$ by $2.46 \mathrm{kcal} / \mathrm{mol}$. (It is not possible to calculate the interactions individually, since the magnitude of the anomeric effect $\mathrm{A}$ in 1,3-dioxane is not known.) A comparable value in cyclohexane is that for the difference of $s y n$-axial $\mathrm{OH} / \mathrm{Me}$ and $\mathrm{OH} / \mathrm{H}$ interactions, which may be calculated to be $1.7 \mathrm{kcal} / \mathrm{mol}^{18}$. That the difference should be greater in the more compressed (vide supra) dioxane molecule is, of course, reasonable.

Whereas $\Delta G^{0}$ for the 2-methoxy-4-methyl- and 2-methoxy-cis-4,6dimethyl-1,3-dioxanes is $0.36-0.41 \mathrm{kcal} / \mathrm{mol}$ (Table 3), the corresponding value for the 5-t-butyl-2-methoxydioxanes, after correction for the conformational inhomogeneity of the trans isomert, is $0.60 \mathrm{kcal} / \mathrm{mole}$. Also, comparison of the dipole moment of the conformationally mobile 2-methoxy1,3-dioxane (Figure 5), 2.24 D, with the average value (1.95 D) for axial (e.g. 1)

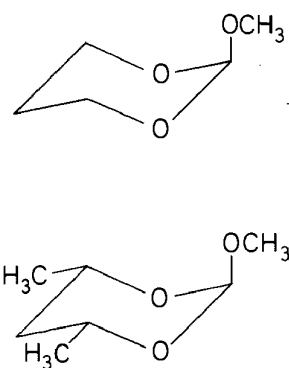

$1,1.970$
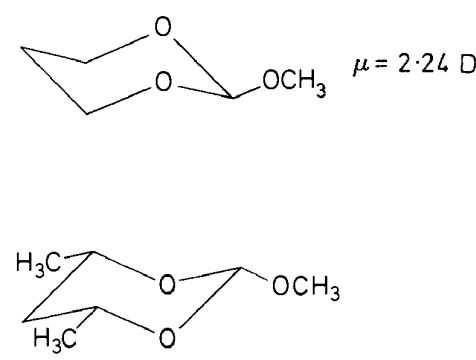

$2,2.930$

Figure 5

and that $(2.91 \mathrm{D})$ for equatorial (e.g. 2) prototypes suggests a $\Delta G^{0}$-value (Figure 4) of $0.62 \mathrm{kcal} / \mathrm{mol}$, using the relationship ${ }^{19} \mu^{2}=N_{\mathrm{e}} \mu_{\mathrm{e}}^{2}+N_{\mathrm{a}} \mu_{\mathrm{a}}^{2}$. It is interesting that the $\Delta G^{0}$-values for the unsubstituted and the 5-t-butylsubstituted 2-methoxy-dioxanes are similar whereas those of the 4- and 4,6-substituted compounds are somewhat biased toward the equatorial

$\dagger$ The cis isomer will exist nearly entirely (ca.95 per cent) in the conformation in which the 5 - $t$-butyl substituent occupies the more stable equatorial conformation and the 2-methoxy group the more stable axial conformation. However, the trans isomer will not be entirely in the diequatorial conformation: it costs ${ }^{1}$ only $1.4 \mathrm{kcal} / \mathrm{mol}$ to shift the 5 - $t$-butyl group into the axial position and $0.4 \mathrm{kcal} / \mathrm{mol}$ is gained back by shifting the 2-methoxy group into the axial position (vide supra), thus $\Delta G_{e e \rightarrow a a}^{0}$ is $1.4-0.4$ or $1.0 \mathrm{kcal} / \mathrm{mol}$ and only about 85 per cent of the molecules will exist in the ee-conformation. The concentration of the $e e$-conformational isomer is therefore 0.85 times the stoichiometric concentration of the trans isomer at equilibrium. In arriving at the $0.60 \mathrm{kcal} / \mathrm{mol}$ figure, the appropriate correction has been iterated for both epimers, even though for the cis compound it is very minor. For the methodology, see E. L. Eliel and R. S. Ro.J. Amer. Chem. Soc. 79, 5992 (1957). 


\section{CONFORMATIONAL ANALYSIS IN HETEROCYCLES}

methoxyl. The situation here is similar to that in cyclohexane $\mathrm{e}^{20}$; an explanation has been given ${ }^{21}$ in terms of a buttressing effect: equatorial substituents at $\mathrm{C}-4$ and $\mathrm{C}-6$ prevent the axial hydrogens at these positions from splaying outward and thus increase their syn-axial interaction with axial substituents at C-2.

The orthoformates shown in Table 3 and Figure 5 are easily prepared from trimethyl orthoformate and the appropriate diols by an ester interchange ${ }^{13-15}$; moreover, diastereoisomers are easily separated because of their large differences in dipole moments which give rise to a correspondingly large difference (about $15^{\circ} \mathrm{C}$ at $20 \mathrm{~mm}$ ) in boiling point ${ }^{22}$. We have studied ${ }^{15}$ the stereochemistry of the reaction of orthoformates with Grignard reagents with the results shown in Figure 6. Axial 2-alkoxy-1,3-dioxanes react very
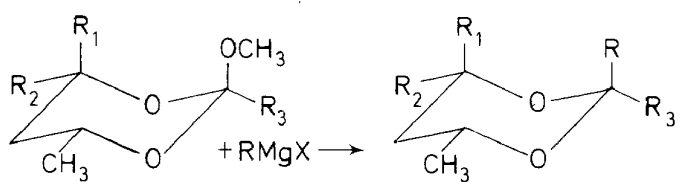

OCH

$$
\mathrm{R}=\mathrm{CH}_{3}, \mathrm{C}_{2} \mathrm{H}_{5},\left(\mathrm{CH}_{3}\right)_{2} \mathrm{CH}, \mathrm{C}_{6} \mathrm{H}_{5}\left[\operatorname{not}\left(\mathrm{CH}_{3}\right)_{3} \mathrm{C}\right]
$$

\section{Figure 6}

readily with Grignard reagents in ether at room temperature to give almost entirely axially substituted 2-alkyl-1,3-dioxanes. Under the same conditions, equatorially substituted 2-alkoxy-1,3-dioxanes are totally inert. The result has been interpreted ${ }^{15}$ in terms of maximum participation of the stereoelectronically favourably disposed axial electron pairs on the ring oxygens in the transition states for formation of the dialk oxy-carbonium ion (Figure 7) and for its reaction with the alkyl anion part of the Grignard reagent.

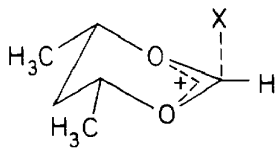

$\mathrm{X}=$ receding $\mathrm{CH}_{3} \mathrm{OMgX}$ or approaching $\mathbf{R}^{-}$(bottomside approach of $\mathrm{R}^{-}$is sterically disfavoured).

Figure 7

The reaction of 2-alkoxy-1,3-dioxanes (either axial isomers, or cis-trans mixtures, the equatorial isomer being inert with Grignard reagents) constitutes the synthesis of choice for 1,3-dioxanes with axial substituents in the 2-position which otherwise, because of the instability of the axial 2-substituent toward acid (cf. Table l), are quite inaccessible. Unfortunately, only reduction takes place with $t$-butylmagnesium chloride and we have not yet been able to synthesize a 1,3-dioxane with an axial $t$-butyl substituent at position 2 .

The reactions of the 2-alkoxy-1,3-dioxanes with lithium aluminium deuteride, aluminium deuteride and dichloroaluminium deuteride have also 
been studied ${ }^{23}$. The rather sluggish reaction with $\mathrm{LiAlD}_{4}$ and the much faster reaction with $\mathrm{AlD}_{3}$ differ substantially in mechanism from the Grignard reactions in that they proceed with predominant retention of configuration (Figure 8), probably through a four-centre mechanism. However, the reaction with $\mathrm{AlCl}_{2} \mathrm{D}$ leads predominantly to the dioxane with axial deuterium.

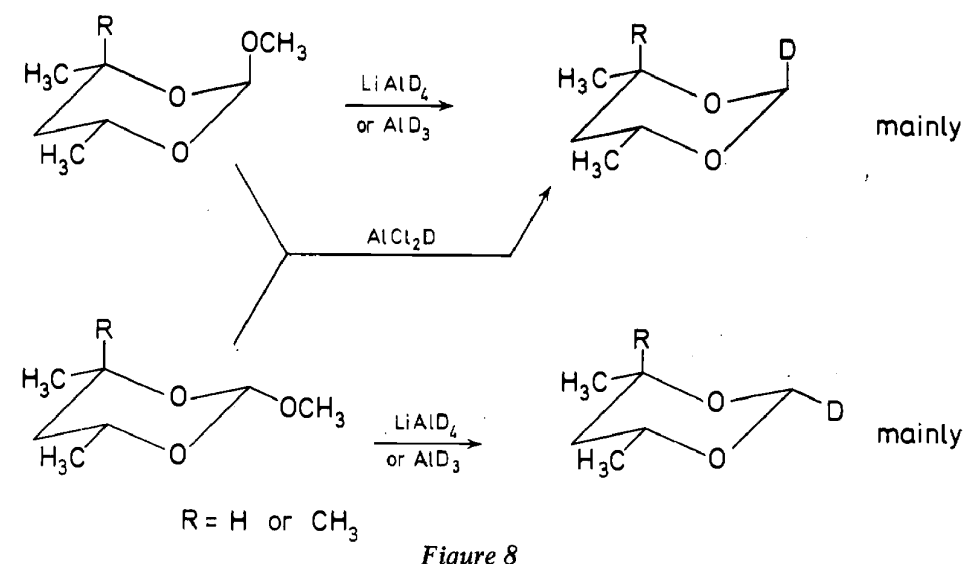

Presumably this reaction, like the reaction with Grignard reagents, proceeds via the dioxocarbonium ion. However, it differs from the Grignard alkylation in that both equatorial and axial 2-alkoxy-1,3-dioxanes react. This may be ascribed either to a lower overall activation energy for the dichloroalane reaction (so that participation of the p-electrons on oxygen becomes less crucial) or less probably to a rapid isomerization by $\mathrm{AlDCl}_{2}$ of the equatorial 2-alkoxydioxane prior to reaction $\uparrow$.

\section{5-SUBSTITUTED 1,3-DIOXANES}

Whereas the 2-substituted 1,3-dioxanes illustrate the interplay of polar factors with strongly repulsive non-bonded interactions, the 5-substituted systems present an interplay of polar factors with van der Waals interactions which are either only weakly repulsive or are actually attractive. A summary of the equilibria studied in 5-substituted 1,3-dioxanes is given in Table $4^{24}$. It should be noted that, whereas in 2-substituted 1,3-dioxanes polar factors favour the axial conformation for an electron-withdrawing substituent, the contrary is true at C-5: because of the direction of the ring dipole, an electronwithdrawing substituent is more favourably disposed, on polar grounds, when equatorial.

A more detailed survey of 5-substituted 1,3-dioxanes is given in the following tables. Table 5 shows the equilibrium for 2-isopropyl-5-hydroxy-1,3dioxane in various solvents $\ddagger$. Because of intramolecular hydrogen bonding ${ }^{25}$,

$\dagger$ In the absence of excess hydride, the 2-alkoxydioxane is rapidly destroyed in the reaction medium.

$\ddagger$ It should be noted that since the $-\Delta G^{0}$-value for isopropyl is $4.2 \mathrm{kcal} / \mathrm{mole}$ (Table 1 ) and that for most of the 5 -substituents studied is $1 \mathrm{kcal} / \mathrm{mol}$ or less, the compounds shown in Table 4 and the following tables are all essentially conformationally biased ('anancomeric ${ }^{26}$ ) toward the conformation with equatorial isopropyl, i.e. isopropyl at C-2 is a good 'holding group'. 
Table 4. Equilibria in 5-substituted 1,3-dioxanes ${ }^{24}$.

\begin{tabular}{|c|c|c|}
\hline $\mathrm{X}$ & $\Delta G_{25}^{0}(\mathbf{k c a l} / \mathrm{mole})$ & $\Delta G_{\mathrm{cyc}}^{0}{ }^{\mathrm{a}}$ \\
\hline $\begin{array}{l}\mathrm{CH}_{3} \\
\mathrm{OH} \\
\mathrm{OMe} \\
\mathrm{OAc} \\
\mathrm{F} \\
\mathrm{Cl} \\
\mathrm{Br} \\
\mathrm{NO}_{2} \\
\mathrm{CN} \\
\mathrm{COOMe} \\
\mathrm{CH}_{2} \mathrm{OH} \\
\mathrm{CH}_{2} \mathrm{OMe}\end{array}$ & $\begin{array}{l}-0.80 \\
+0.89\left(\mathrm{C}_{6} \mathrm{H}_{12}\right) \\
-0.83 \\
0.0 \\
+0.62 \\
-1.20 \\
-1.44 \\
+0.38\left(\mathrm{CCl}_{4}\right) \\
-0.21 \\
-0.82 \\
+0.27\left(\mathrm{CCl}_{4}\right) \\
-0.05\end{array}$ & $\begin{array}{l}-1.70 \\
-0.52 \\
-0.60 \\
-0.60 \\
-0.15 \\
-0.43 \\
-0.38 \\
-1.10 \\
-0.17 \\
-1.27 \\
-1.65 \\
?\end{array}$ \\
\hline
\end{tabular}

a Corresponding values in cyclohexyl-X: J. A. Hirsch in Topics in Stereochemistry, Vol. 1, chap. 4. N. L. Allinger and E. L. Eliel, (eds). Interscience Wiley: New York (1967).

the axial position of the hydroxyl group is preferred. The preference in an aprotic solvent (cyclohexane) is somewhat lessened as the concentration is increased, as the equatorial isomer gains in energy through intermolecular hydrogen bonding; a similar situation is observed in 4-t-butylcyclohexanol ${ }^{18}$. The equatorial isomer is actually favoured in a hydrogen donor solvent (alcohol), presumably because hydrogen bonding from solvent to hydroxydioxane is more effective when the hydroxyl group is equatorial than when it is axial. Again this situation has its parallel in cyclohexano ${ }^{18}{ }^{8}$, but the effect is much more marked in the 5-hydroxy-1,3-dioxane, presumably because the intramolecular hydrogen bond stabilizing the axial isomer is replaced by intermolecular hydrogen bonds stabilizing the equatorial one. A similar situation is found in solvent 1,2-dimethoxyethane and, though to a lesser extent, in solvent acetonitrile. These solvents must of course function as hydrogen acceptors.

Table 5. Conformational energy of hydroxyl ${ }^{24}$.

\begin{tabular}{|c|c|c|c|}
\hline Solvent & $\begin{array}{c}\text { Conc. } \\
M\end{array}$ & $\underset{\mathrm{kcal} / \mathrm{mol}}{\Delta G_{25}^{0}}$ & $\Delta G_{\mathrm{cyc}}^{0 \mathrm{a}}$ \\
\hline $\mathrm{C}_{6} \mathrm{H}_{12}$ & $\begin{array}{l}0.05 \\
0.10 \\
0.20\end{array}$ & $\begin{array}{l}+0.89 \\
+0.86 \\
+0.81\end{array}$ & $\begin{array}{l}-0.60 \\
-0.61 \\
-0.61\end{array}$ \\
\hline $\begin{array}{l}\mathrm{CH}_{3} \mathrm{CN} \\
\left(\mathrm{MeOCH}_{2}\right)_{2} \\
i-\mathrm{PrOH}\end{array}$ & $\begin{array}{l}0 \cdot 10 \\
0 \cdot 10 \\
0 \cdot 10\end{array}$ & $\begin{array}{l}+0.04 \\
-0.51 \\
-0.71\end{array}$ & $\begin{array}{l}- \\
-0.74 \\
-0.95\end{array}$ \\
\hline
\end{tabular}

- Corresponding value in $\mathrm{C}_{6} \mathrm{H}_{11} \mathrm{OH}$, ref. 18 . 
The equilibria of the 2-isopropyl-5-methoxy-1,3-dioxanes in various solvents are tabulated in Table 6. The results show a (not very smooth) dependence of $\Delta G^{\circ}$ on solvent dielectric constant ${ }^{\dagger}$. It appears that the strong preference of methoxyl for the equatorial position in solvent carbon tetrachloride is largely due to a dipole interaction, for in the high-dielectric solvent acetonitrile there is almost no difference in free energy between

Table 6. Conformational energy of methoxy ${ }^{25}$

\begin{tabular}{lrc}
\hline & & \\
\multicolumn{1}{c}{ Solvent } & $\varepsilon_{25}$ & $\Delta G_{25}^{\circ}(\mathbf{k c a l} / \mathrm{mol})$ \\
\hline $\mathrm{CCl}_{4}$ & 2.2 & -0.89 \\
$\mathrm{Et}_{2} \mathrm{O}$ & 4.3 & -0.83 \\
$\mathrm{CHCl}_{3}$ & 4.8 & -0.18 \\
$\mathrm{CH}_{3} \mathrm{OH}$ & 32.6 & -0.03 \\
$\mathrm{CH}_{3} \mathrm{CN}$ & 37.5 & +0.01 \\
\hline
\end{tabular}

equatorial and axial methoxyl; in other words, the non-bonded (as distinct from dipolar) forces, if anything, slightly favour the axial isomer, in contrast to the situation in methoxycyclohexane where the equatorial conformation is preferred ${ }^{18}$ (see Table 4). The result is of particular interest because of the question of the relative magnitude of lone pair/lone pair interaction in comparison with, say, atom/atom and atom/lone pair interactions. The situation is summarized in Figure 9. The axial conformation of methylcyclohexane displays two syn-axial methyl/hydrogen interactions (atom/atom) of 0.85 $\mathrm{kcal} / \mathrm{mol}$ each. The corresponding hydroxyl/hydrogen interaction in cyclohexanol or 5 -methyldioxane (atom/pair) is 0.3 to $0.4 \mathrm{kcal} / \mathrm{mol}$. The related pair/pair (oxygen/oxygen) interaction in 5-methoxy-1,3-dioxane (axial conformation) is very nearly zero, or at least the interaction for axial $\mathrm{OMe}$ is no greater than that for equatorial OMe.

$\Delta G^{0}$-values of other 5-substituents as a function of solvent are shown in Table $7^{24}$. A complete interpretation of these data is not yet possible; for example, it is rather puzzling why fluorine with its relatively low polarizability prefers the axial conformation even in a solvent of such low polarity as ether whereas the more polarizable chlorine and bromine, which engender similar dipoles and are effectively only slightly larger in cyclohexyl halides, prefer the equatorial position, the difference being of the order of $2 \mathrm{kcal} / \mathrm{mol}$. Strong solvent effects are found with almost all the substituents, the equatorial preference being least (or the axial preference greatest) in solvents of

$\dagger$ The quantitatively predicted effect of solvent dielectric on $\Delta G^{0}$ is complex. For a recent discussion, see ref. 27. 
CONFORMATIONAL ANALYSIS IN HETEROCYCLES

Atom - atom<smiles>CNC1CC2CCCC(C2)C1</smiles>

$\mathrm{kcal} / \mathrm{mol}$

Atom - pair<smiles>CO[C@H]1CC[C@H]2CC[C@H]1C2</smiles>

or<smiles>CC1COCCO1</smiles>

Pair - pair<smiles>COCC1COOCC1OC</smiles>

Atom/atom $>$ atom/pair $>$ pair $/$ pair

Figure 9

high dielectric constant, as already explained in the case of $\mathrm{CH}_{3} \mathrm{O}$. The substantial preference of $\mathrm{NO}_{2}$ and $\mathrm{CN}$ for the axial position (in the case of $\mathrm{CN}$ only in the case of a high-dielectric solvent) is particularly interesting

Table 7. Dependence of conformational energies on solvent ${ }^{25}$.

\begin{tabular}{|c|c|c|c|c|}
\hline $\mathrm{X}$ & Solvent & $\varepsilon_{25}$ & $\Delta G_{25}^{0}$ & $\Delta G_{\mathrm{cyc}}^{0{ }^{\mathrm{a}}}$ \\
\hline \multirow[t]{4}{*}{$\mathrm{F}$} & $\mathrm{CH}_{3} \mathrm{CN}$ & $37 \cdot 5$ & $+1 \cdot 22$ & \multirow{4}{*}{$(-0.15)$} \\
\hline & $\mathrm{CH}_{3} \mathrm{OH}$ & $32 \cdot 6$ & +0.60 & \\
\hline & $\mathrm{C}_{6} \mathrm{H}_{6}$ & $2 \cdot 3$ & +0.83 & \\
\hline & $\mathrm{Et}_{2} \mathrm{O}$ & 43 & +0.62 & \\
\hline $\mathrm{Cl}$ & $\mathrm{Et}_{2} \mathrm{O}$ & $4 \cdot 3$ & $-1 \cdot 20$ & $(-0.43)$ \\
\hline $\mathrm{Br}$ & $\mathrm{Et}_{2} \mathrm{O}$ & $4 \cdot 3$ & -1.44 & $(-0.38)$ \\
\hline \multirow[t]{3}{*}{$\mathrm{NO}_{2}$} & $\mathrm{CCl}_{4}$ & $2 \cdot 2$ & $+0 \cdot 38$ & \\
\hline & $\mathrm{CHCl}_{3}$ & 4.8 & +0.63 & $(-1: 10)$ \\
\hline & $\mathrm{CH}_{2} \mathrm{Cl}_{2}$ & $9 \cdot 1$ & +0.81 & \\
\hline \multirow[t]{2}{*}{$\mathrm{CN}$} & $\mathrm{Et}_{2} \mathrm{O}$ & 43 & -0.21 & $(-0.17)$ \\
\hline & $\mathrm{CH}_{3} \mathrm{CN}$ & $37 \cdot 5$ & +0.55 & \\
\hline \multirow[t]{2}{*}{ COOMe } & $\mathrm{Et}_{2} \mathrm{O}$ & $4 \cdot 3$ & -0.82 & $(-1 \cdot 27)$ \\
\hline & $\mathrm{CH}_{3} \mathrm{CN}$ & 37.5 & -0.22 & \\
\hline \multirow[t]{2}{*}{$\mathrm{CH}_{2} \mathrm{OH}$} & $\mathrm{CCl}_{4}$ & $2 \cdot 2$ & +0.27 & $(-1 \cdot 65)$ \\
\hline & $\left(\mathrm{MeOCH}_{2}\right)_{2}$ & 6.8 & -0.01 & $(-2 \cdot 06)$ \\
\hline $\mathrm{CH}_{2} \mathrm{OMe}$ & $\mathrm{Et}_{2} \mathrm{O}$ & 43 & -0.05 & \\
\hline
\end{tabular}

a Corresponding value in $\mathrm{C}_{6} \mathrm{H}_{1} \mathrm{X}$. 
and tends to suggest that there may be an attractive interaction between the pi-electron clouds in these functional groups and the $p$-electrons of oxygen $\dagger$.

The fact that $\mathrm{CH}_{2} \mathrm{OH}$ is more biased toward the axial position in the nonhydrogen-bonding solvent carbon tetrachloride than in the hydrogen acceptor dimethoxyethane might, at first sight, suggest that intramolecular hydrogen bonding is responsible for the axial preference, as had, in fact, been postulated ${ }^{28 a}$ for the axial preference of $\mathrm{CH}_{2} \mathrm{OH}$ over $\mathrm{CH}_{3}$ in 5-hydroxymethyl-5-methyl1,3-dioxane. However, it should be noted (Table 7) that there is a similarity in $\Delta G^{0}$ between $\mathrm{CH}_{2} \mathrm{OH}$ and $\mathrm{CH}_{2} \mathrm{OMe}$; in addition the solvent dependence of the $\mathrm{CH}_{2} \mathrm{OH}$ group is not very different from that in cyclohexylmethanol ${ }^{29}$ : $-\Delta G^{0}=1.65 \mathrm{kcal} / \mathrm{mol}$ in cyclohexane, $2.06 \mathrm{kcal} / \mathrm{mol}$ in isopropyl alcohol. Moreover, attempts to put into evidence an intramolecular hydrogen bond in cis-5-hydroxymethyl-2-isopropyl-1,3-dioxane surprisingly proved to be quite fruitless ${ }^{24}$ : the compound, in dilute carbon tetrachloride solution, shows a single $\mathrm{OH}$-stretching band in the infra-red at $3643 \mathrm{~cm}^{-1}$ which is exactly the same frequency where the $\mathrm{OH}$-stretching frequency of the corresponding trans isomer is found ${ }^{28 b}$. It would appear that steric or dipolar factors prevent the axial $\mathrm{CH}_{2} \mathrm{OH}$ group from pointing into the ring in a position suitable for bonding to one of the ring oxygens ${ }^{28 b}$

\section{GEMINALLY DISUBSTITUTED 1,3-DIOXANES}

The study of conformational preferences in geminally disubstituted cyclohexanes has been experimentally difficult ${ }^{30}$. In contrast, the facile equilibration of epimers in the 1,3-dioxane series may be easily extended to geminally disubstituted species. 2,2-Disubstituted 1,3-dioxanes are readily available from 1,3-diols and ketones (cf. Figure 1), appropriate diols for synthesis of 4,4-disubstituted 1,3-dioxanes are available by the Prins reaction ${ }^{31}$, and the diols required for preparation of 5,5-disubstituted dioxanes are easily prepared either by the Tollens condensation of an alpha-branched aldehyde with formaldehyde or by reduction of dialkylmalonic esters. We have studied ${ }^{32}$ a series of 5,5-disubstituted compounds, using an isopropyl group at C-2 as the holding group; the results of equilibration are shown in Table 8. As had been found previously ${ }^{30 a}$, the $\Delta G^{0}$-values for rotamerically nonsymmetrical substituents (e.g. ethyl, isopropyl, phenyl) are not additive $\left(\Delta G^{0}\right.$ values computed by subtracting $\Delta G_{\mathrm{R}^{\prime}}^{0}$ are shown, for comparison, in the last column of Table 8). The reason for non-additivity is that certain rotational conformations which are favoured in the monosubstituted rings become unfavourable in the geminally disubstituted compounds because of geminal interactions; as a result, the substituents are forced into less favourable rotational arrangements and become effectively 'larger, ${ }^{33}$. An example for an equatorial ethyl group is shown in Figure 10 (for any-unspecified--

$\dagger$ We had at one time thought that the preference of $\mathrm{NO}_{2}$ (which has a very large group dipole of 3.3 D) for the axial position indicated a Coulombic attraction between the positive end of the $\mathrm{NO}_{2}$ dipole and the electron clouds around the ring oxygen. However, the finding that the axial conformation is preferred more, rather than less, in a solvent of high dielectric constant speaks against a Coulombic interpretation. 


\section{CONFORMATIONAL ANALYSIS IN HETEROCYCLES}

Table 8. Dioxanes with geminal substituents in the 5-position ${ }^{32}$.

\begin{tabular}{|c|c|c|c|c|}
\hline $\mathbf{R}$ & $\mathbf{R}^{\prime}$ & $\begin{array}{l}\Delta G^{0} \\
\text { exp. }\end{array}$ & $\begin{array}{l}\Delta G^{0} \\
\text { calc. }\end{array}$ & $\begin{array}{l}\Delta G^{0} \\
\text { add }\end{array}$ \\
\hline $\begin{array}{l}\mathrm{CH}_{3} \\
\mathrm{CH}_{3} \\
\mathrm{CH}_{3} \\
\mathrm{CH}_{3} \\
\mathrm{C}_{2} \mathrm{H}_{5} \\
\mathrm{C}_{2} \mathrm{H}_{5} \\
\mathrm{OH} \\
\mathrm{CH}_{3} \mathrm{O} \\
\mathrm{CH}_{2} \mathrm{OH} \\
\mathrm{CH}_{2} \mathrm{OCH}_{3} \\
\mathrm{NO}_{2}\end{array}$ & $\begin{array}{l}\mathrm{C}_{2} \mathrm{H}_{3} \\
\left(\mathrm{CH}_{3}\right)_{2} \mathrm{CH} \\
\left(\mathrm{CH}_{3}\right)_{3} \mathrm{C} \\
\mathrm{C}_{6} \mathrm{H}_{5} \\
\left(\mathrm{CH}_{3}\right)_{2} \mathrm{CH} \\
\mathrm{C}_{6} \mathrm{H}_{5} \\
\mathrm{CH}_{3} \\
\mathrm{CH}_{3} \\
\mathrm{CH}_{3} \\
\mathrm{CH}_{3} \\
\mathrm{CH}_{3}\end{array}$ & $\begin{array}{l}+0.06 \\
-0.30 \\
-0.81 \\
-0.54 \\
-0.32 \\
-0.51 \\
-0.41 \\
+0.34 \\
-0.68 \\
-0.63 \\
-0.43^{\mathrm{a}}\end{array}$ & $\begin{array}{c}0 \cdot 14 \\
0 \cdot 33 \\
-0 \cdot 60 \\
? \\
-0 \cdot 33 \\
? \\
? \\
? \\
? \\
? \\
?\end{array}$ & $\begin{array}{l}+0.13 \\
-0.18 \\
-0.60 \\
-0.23 \\
-0.18 \\
-0.36 \\
-0.49 \\
-0.07 \\
-0.87 \\
-0.85 \\
-1.24\end{array}$ \\
\hline
\end{tabular}

a in $\mathrm{CCl}_{4}$. Other values are in ether.

six-membered ring): when $\mathrm{R}=\mathrm{H}$ (monosubstituted ring), the favoured conformation of the ethyl group is $\mathbf{A}$ or its mirror image (where there is a single gauche interaction of the terminal methyl with the ring) rather than B (where there are two unfavourable gauche interactions), but when $\mathrm{R}=\mathrm{Me}$ (geminally disubstituted ring) and extra gauche interaction is introduced in $\mathbf{A}$ but not in $\mathbf{B}$, the energy advantage of $\mathbf{A}$ is destroyed, the rotational populations of the three rotamers are equalized and the overall energy of the equatorial ethyl group is increased.

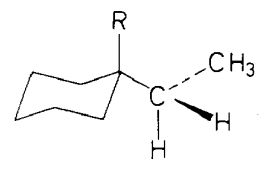

A

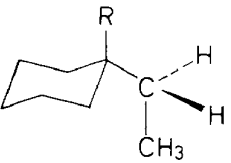

B

Figure 10

The fourth column in Table 8 gives the calculated $\Delta G^{0}$ taking into account all pertinent rotameric restrictions with the assumption that apart from these restrictions, $\Delta G^{0}$ is the same as in a monosubstituted dioxane and setting the value of a gauche interaction as one-half the value of a syn-axial interaction. Unfortunately the difference between the additive values (column 5) and the calculated values (column 4). is not very large and it cannot really be claimed that the agreement with the latter is, overall, materially better than that with the former (it is slightly better in two cases and slightly less good in one). What is perhaps more striking is that even in the cases of rotamerically symmetrical groups, such as methyl and $t$-butyl, where $\Delta G^{0}$-values should be additive, appreciable deviations are found. It would appear, then, that buttressing or other interaction effects interfere with additivity of $\Delta G^{0}$ values even in these circumstances ${ }^{34}$. Further work in the area of geminally disubstituted dioxanes is clearly called for and is under way. 


\section{FOUR-COMPONENT EQUILIBRIA ${ }^{35}$}

It occurred to us that the 1,3-dioxane system lends itself to the study of fourcomponent equilibria of the type shown in Figure 11. The mechanism of establishment of such equilibria is evidently slightly more complex than that for the simple equilibria shown in Figure 2; somewhere along the line, following oxocarbonium formation, a bimolecular reaction followed by an interchange of diol (or carbonyl) components must occur, and, in fact, the equilibria are reached more slowly than the simple ones discussed so far and require higher concentrations of substrates. Whereas the cases shown in Figure 11 merely serve to test the feasibility of the method (the predicted

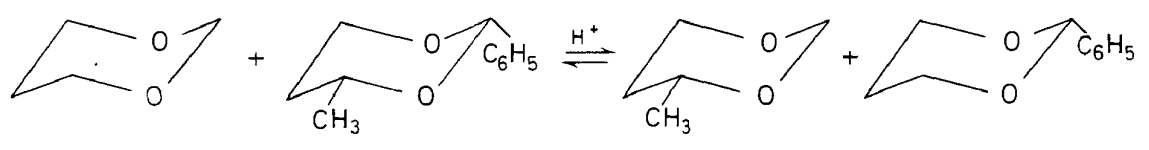

$K=0.99$

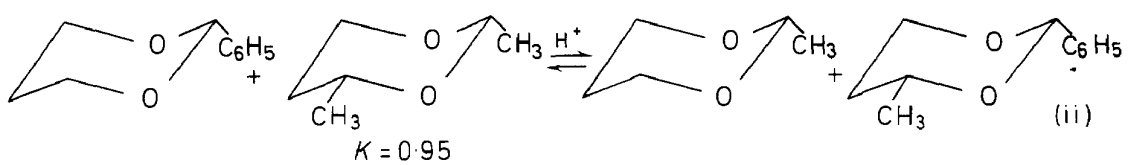

Figure 11

$K$ is unity), some more interesting combinations are shown in Figure 12. The four-component equilibria result in a switch of the diol and the carbonyl parts of two different 1,3-dioxanes. In this way, one may study situations not accessible by simple equilibration. In particular, we are able to study buttressing effects, as in (iii) directly and we can assess quantitatively interactions which are too large to lend themselves to study by simple equilibration, as in (iv). In the latter situation, the very large syn-axial (or twist-boat) interaction on the left-hand side is partially compensated by the $\mathrm{Me}-2$ / $\mathrm{H} / \mathrm{H}$ and $\mathrm{Me}-4 / \mathrm{H} / \mathrm{H}$ interactions on the right ; the sum of these latter interactions amounts ${ }^{1,10}$ to $69 \mathrm{kcal} / \mathrm{mol}$ and the interaction in 3 on the left becomes accessible to experimental study even though it is as large as $7 \cdot 2$ $\mathrm{kcal} / \mathrm{mol}$.

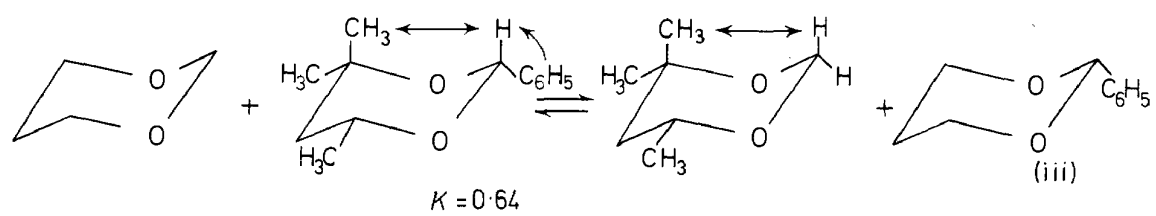<smiles>CC(C)OC(C)OC(C)C</smiles>

$7 \cdot 2$

or twist boat

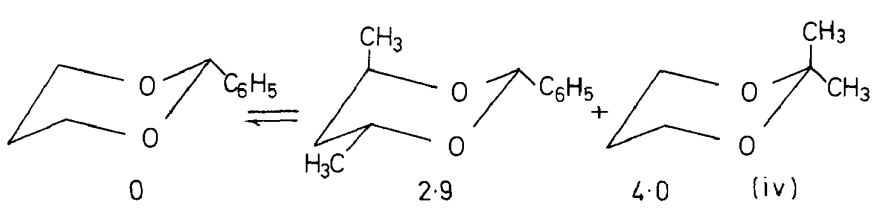

$\Delta G^{0}=-0.28 \mathrm{kcal} / \mathrm{mol}$

Figure 12 
The conformational $\Delta G$-value of $7 \cdot 2 \mathrm{kcal} / \mathrm{mol}$ for the tetramethyldioxane 3 (Figure 12) superficially appears to agree with the heat-of-combustion value of $7.1 \mathrm{kcal} / \mathrm{mol}$ recently determined by Pihlaja and co-workers ${ }^{36}$ However, Pihlaja's value represents $\Delta H$ and should agree with $\Delta G$ only if the conformational entropy $\Delta S=0$. It is hard to see how this can be true if 3 exists in the flexible form; the conformational entropy of this form should be at least 3.5 e.u. ${ }^{36}$ so that a $\Delta G_{25}$-value of $7.2 \mathrm{kcal} / \mathrm{mol}$ would require $\Delta H=8.3 \mathrm{kcal} / \mathrm{mol}$. One is forced to conclude that either Pihlaja's experimental $\Delta H$-value for 3 is too small, or 3 exists as a deformed chair rather than a twist-boat and does not have a large conformational entropy.

There is another finding ${ }^{10}$ suggesting that the $\Delta H=7 \cdot 1 \mathrm{kcal} / \mathrm{mol}$ value ${ }^{36}$ for the twist form in 1,3-dioxane is too low. Equilibration of the 2,4,4,6tetramethyl-1.3-dioxanes (4, Figure 13) produces no palpable amount of the

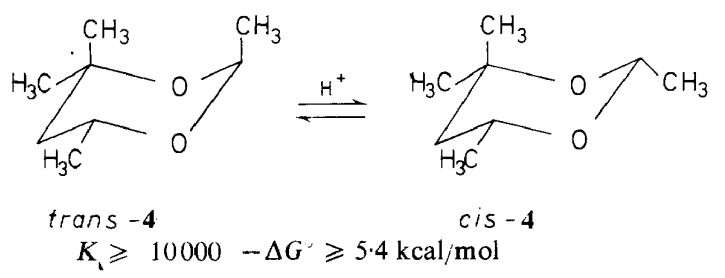

Figure 13

trans isomer at equilibrium (reached from either side) from which one may conclude that $-\Delta G^{0}$ for the process shown in Figure 13 exceeds $5.4 \mathrm{kcal} /$ $\mathrm{mol}^{10}$. Adding $2.9 \mathrm{kcal} / \mathrm{mol}$ for the residual interaction on the right (Figure 13), the interaction on the left (in trans -4 ) must exceed $8.3 \mathrm{kcal} / \mathrm{mol}$. Even if the boat form of trans $\mathbf{4}$ has a residual conformational energy of 0.9 $\mathrm{kcal} / \mathrm{mol}$ (syn-axial Me-4/H-6), if trans -4 exists as a boat $\dagger$, the conformational energy of the boat must amount to no less than $7.4 \mathrm{kcal} / \mathrm{mol}$ and its conformational enthalpy must therefore be probably well in excess of $8 \mathrm{kcal} / \mathrm{mol}$, even allowing for the fact that equatorial methyl groups at C-4 and C-6 tend to make the boat form rather stiff and thus reduce its conformational entropy ${ }^{2}$.

The combined thrust of the arguments is to suggest that $\Delta H_{\text {boat }}$ in 1,3dioxane is well in excess of $8 \mathrm{kcal} / \mathrm{mol}$; if $\mathbf{3}$ and trans $\mathbf{- 4}$ are, in fact, in the twist or boat form, this follows directly from the above arguments; if either 3 or trans $\mathbf{4}$ or both are in deformed chair forms rather than in boat forms, this fact by itself puts a minimum value of $8 \mathrm{kcal} / \mathrm{mol}$ on the instability of the boat form. The reason for the greater instability of the 1,3-dioxane boat or skew-boat form compared to that in cyclohexane $\left(5.9 \mathrm{kcal} / \mathrm{mol}^{37}\right)$ may be sought in the greater compactness of the dioxane molecule which enhances the contribution which transannular interactions make to the high energy of the boat form.

$\dagger$ The coupling constants $J_{4,5}$ for trans $-4,6.8$ and $7.9 \mathrm{~Hz}$ at $39^{\circ} \mathrm{C}$ (ref. 10), suggest the compound exists as a twist form at room temperature. The coupling constants are highly temperature dependent (values at $-83^{\circ} \mathrm{C} 9.5$ and $5.1 \mathrm{~Hz}$, at $+147^{\circ} \mathrm{C} 7.3$ and $7.3 \mathrm{~Hz}$ ) suggesting a transition from chair to flexible boat or from stiff boat to flexible boat as the temperature rises ${ }^{10}$. 


\section{ACKNOWLEDGEMENTS}

We thank the donors of the Petroleum Research Fund administered by the American Chemical Society (Grant 2272-C), the Air Force Office of Scientific Research (Grant AF-AFOSR-772), the National Science Foundation (Grant GP-9379), the Office of Ordnance Research, U.S. Army (Grant DA-ARO D-31-124-G1108) and the Warner-Lambert Pharmaceutical Company for financial support of this research.

\section{REFERENCES}

1 E. L. Eliel and M. C. Knoeber, J. Amer. Chem. Soc, 88, 5347 (1966); 90, 3444 (1968).

2 E. L. Eliel and R. O. Hutchins, J. Amer. Chem. Sö. 91, 2703 (1969).

3 F. G. Riddell, Quart. Rev. Chem. Soc. (London), 21, 364 (1967). See also A. R. Katritzky in Topics in Heterocyclic Chemistry, pp 35-55. R. N. Castle (ed.), Wiley/Interscience: New York (1969).

4 C. Romers, C. Altona, H. R. Buys and E. Havinga in Topics in Stereochemistry, Vol. 4. E. L. Eliel and N. L. Allinger, (eds), Wiley: New York (1969).

5 E. L. Eliel, Kemisk Tidskrift, 81 (No. 6/7), 22 (1969).

6 E. L. Eliel, Accounts of Chemical Research. 3, 1 (1970).

7 cf. R. G. Pearson and J. Songstad, J. Amer. Chem. Soc., 89, 1827 (1967); R. G. Pearson, in Survey of Progress in Chemistry, Vol. 5, pp 1-52. A. F. Scott (ed.), Academic Press: New York (1969).

8 A. Hartmann, unpublished observations.

9 a F. H. Westheimer in Steric Effects in Organic Chemistry, M. S. Newman (ed.), Wiley: New York (1956).

${ }^{b}$ cf. J. P. Lowe, in Progress in Physical Organic Chemistry, Vol. 5, pp 1-80. A. Streitwieser and R. W. Taft, (eds), Interscience: New York (1968).

10 F. W. Nader and E. L. Eliel, J. Amer. Chem. Soc. 92, 3050 (1970).

11 A. J. de Kok and C. Romers, Rec. Trav. Chim. Pays-Bas, 89, 313 (1970)

12 W. F. Bailey, J. M. McKenna and E. L. Eliel, unpublished observations.

13 Sr. M. C. Knoeber, Ph. D. Dissertation, University of Notre Dame, Notre Dame, Indiana (1967).

14 E. L. Eliel and C. Giza, J. Org. Chem. 33, 3754 (1968).

15 See also E. L. Eliel and F. W. Nader, J. Amer. Chem. Soc. 91, 536 (1969); 92,584 (1970).

16 cf. R. U. Lemieux in Molecular Rearrangements, Chapter 12. Interscience/Wiley: New York (1964). S. J. Angyal, Angew. Chem. 81, 172 (1969); Angew. Chem. Internat. Ed. Engl. 8, 157 (1969).

17 R. O. Hutchins. L. Kopp and E. L. Eliel, J. Amer. Chem. Soc. 90, 7174 (1968). We now (1971) prefer to call this effect 'generalized anomeric effect'.

18 a E. L. Eliel and E. C. Gilbert, J. Amer. Chem. Soc. 91, 5487 (1969). This value refers to cyclohexane as a solvent and is somewhat less than the values 1.9 to $2.4 \mathrm{kcal} / \mathrm{mol}$ reported in $b$

${ }^{b}$ E. L. Eliel, N. L. Allinger, S. J. Angyal and G. A. Morrison, Conformational Analysis, p 52. Interscience/Wiley: New York (1965), which refers to isopropyl alcohol as solvent.

19 cf. ref. $18 \mathrm{~b}, \mathrm{p} 159$.

20 E. E. Eliel and T. J. Brett, J. Amer. Chem. Soc. 87, 5039 (1965).

21 N. L. Allinger, M. A. Miller, F. A. VanCatledge and J. A. Hirsch, J. Amer. Chem. Soc. 89, 4345 (1967).

22 According to the van Arkel or dipole rule; cf. E. L: Eliel, Stereochemistry of Carbon Compounds, pp 327-328. McGraw-Hill : New York (1962).

23 E. L. Eliel and F. W. Nader, J. Amer. Chem. Soc. 92, 3045 (1970).

24 E. L. Eliel and M. K. Kaloustian, Chem. Commun. 290 (1970);-regarding the 5-hydroxy and 5-alkoxy compounds see also ref. 25.

25 N. Baggett, J. S. Brimacombe, A. B. Foster, M. Stacey and D. H. Whiffen, J. Chem. Soc. 2574 (1960). These authors investigated the 2-phenyl compound.

26 See M. Anteunis, D. Tavernier and F. Borremans. Bull. Soc. Chim. Belges, 75, 396 (1966). 


\section{CONFORMATIONAL ANALYSIS IN HETEROCYCLES}

27 R. J. Abraham, L. Cavalli and K. G. R. Pachler, Molec. Phys. 11, 471 (1966). See also S. Mizushima, Structure of Molecules and Internal Rotation, pp 42-45. Academic Press: New York (1954).

28 J.-C. Duplan, J. Delmau and M. Davidson, Bull. Soc. Chim. France, 4081 (1968). This suggestion has now been withdrawn: J. Delman, personal communication. ${ }^{b}$ See also R. Dratler and P. Laszlo, Tetrahedron Letters, 2607 (1970); E. L. Eliel and H. D. Banks, J. Amer. Chem. Soc. 92, 4730 (1970).

29 E. L. Eliel, D. C. Neilson and E. C. Gilbert, Chem. Commun. 360 (1968).

30 See, however, ${ }^{a}$ S. Sicsic and Z. Welvart, Bull. Soc. Chim. France, $575(1967){ }^{b}$ N. L. Allinger and C. D. Liang, J: Org. Chem. 32, 2391 (1967).

31 cf. E. Arundale and L. A. Mikeska, Chem, Revs 51, 505 (1952).

32 R. M. Enanoza, Ph.D. Dissertation, University of Notre Dame (1970).

33 This point was first clearly expressed in print by R. D. Stolow, J. Amer. Chem. Soc. 86, 2170 (1964).

34 For a discussion of a similar situation, see J. P. Mazaleyrat and Z. Welvart, Chem. Commun. 485 (1969).

35 F. W. Nader and J. R. Powers, unpublished observations.

36 K. Pihlaja and S. Luoma, Acta Chem. Scand. 22, 2401 (1968).

37 N. L. Allinger and L. A. Freiberg, J. Amer. Chem. Soc. 82, 2393 (1960). 